DOI 10.37882/2223-2982.2021.06.31

\title{
МОТИВАЦИОННОЕ ЭССЕ: ОСОБЕННОСТИ ЖАНРА И ПЕРЕВОДА (НА МАТЕРИАЛЕ ПРОИЗВЕДЕНИЯ РАЙАНА ХОЛИДЕЯ «КАК ЭГО МОЖЕТ СТАТЬ НАШИМ ВРАГОМ»)
}

\section{MOTIVATION ESSAY: PECULIAR FEATURES OF THE GENRE AND TRANSLATION (BASED ON RYAN HOLIDAY'S ESSAY "EGO IS THE ENEMY")}

N. Pokrovskaia

Summary: In this paper, the object of research is a motivation essay analyzed from the standpoint of genre and stylistic features and translation. The article presents the characteristics of the essay, typical features of the English-language motivational discourse, definition of the motivational essay and the main ways of its verbalization and implementation of the leading function of pervasiveness on the example of the work of the modern American writer Ryan Holiday. The main factors important for translators are formulated on the basis of the identified characteristic features of the English-language motivation essay.

Keywords: Ryan Holiday, essay genre, motivational English-language discourse, motivation essay, stylistic features, translation difficulties.

\author{
Покровская Наталья Владимировна \\ Соискатель, Казанский (Приволжский) \\ федеральный университет \\ nataliavladimirovnapokrovskaia@gmail.com
}

Аннотация: Объектом исследования в данной работе выступает мотивационное эссе, анализируемое с позиции жанрово-стилистических особенностей и перевода. В статье представлена характеристика эссе, типичные черты англоязычного мотивационного дискурса, дано определение мотивационного эссе и рассмотрены основные способы его вербализации и реализации ведущей функции персуазивности на примере произведения современного американского писателя Райана Холидея. Сучетом выявленных характерных черт англоязычного мотивационного эссе сформулированы основные факторы, учет которых рекомендуется при переводе произведений такого типа.

Ключевые слова: Райан Холидей, жанр эссе, мотивационный англоязычный дискурс, мотивационное эссе, стилистические особенности, трудности перевода.
$\mathrm{P}$ айан Холидей (Ryan Holiday) - современный американский писатель, известный оратор, маркетолог, журналист, автор множества бестселлеров. Его книги переведены на 30 языков мира, а читательская аудитория составляет более 2 миллионов человек. В центре внимания автора вопросы самосовершенствования, развития личности и лидерских качеств, преодоление жизненных трудностей, способы достижения успеха и поставленных целей. В 2016 году было впервые опубликовано его произведение «Как эго может стать нашим врагом» ("Ego is the Enemy"), которое сам автор отнес к жанру мотивационного эссе. Книга оценивается многими критиками как одно из лучших произведений современности, а сам автор - тонким мыслителем своего поколения.

Чем обусловлена популярность этого жанра в наши дни? Какие жанрово-стилистические и прагматические особенности позволяют относить то или иное произведение к мотивационному эссе? Как эти особенности учитываются в процессе переводческой деятельности?

В американском словаре Merriam-Webster под эссе понимается «аналитическое или интерпретативное литературное произведение, построенное на субъективной точке зрения или мнении ограниченной группы лиц». В XIV веке слово заимствуется английским языком из французского в значении «испытание», «попытка» ('essai'), которое, в свою очередь, восходит к латинскому 'exagium' - «взвешивание» [Merriam-Webster].

Первое понимание жанра закладывается во Франции в XVI веке. В основе эссеистики, пишет А. Добрянская, заложены, прежде всего, подвижность ассоциаций, установка на интимную откровенность и разговорную интонацию [Добрянская, 2018]. В последнее время отмечается заметный рост внимания к жанру эссе и в целом к проблеме дифференциации речевых жанров, что связано с возросшей ролью устного общения и динамическими процессами в письменной речи. Как отмечает Р.А. Каримова, современная словесность отмечена новациями в сфере языковой личности и активным появлением пограничных жанровых видов, среди которых видное место отводится эссеистике [Каримова, 2019: 872].

Неявная выраженная жанровая принадлежность эссе, обусловленная его пограничным состоянием, вызывает понятийную размытость термина, указывает на «всеядность» жанра, его бесструктурность, «блуждающую сущность» и т.п., на что указывают многие исследователи (Л.Д. Кайда, Т.Ю. Лямзина, М. Эпштейн и др.). Вместе с тем авторы выделяют ряд устойчивых жанровых 
характеристик, среди которых малая форма произведения, четкая сконцентрированность на определенной, часто актуальной теме, ярко выраженная авторская позиция, свободная композиционная форма, разнообразие средств выразительности, доминирование функции убеждения [Тихонова, 2016: 71-72]. Интегративность в эссе обеспечивается личностью самого повествователя, чьи эмоции и знания становятся основным структурообразующим элементом, вокруг которого происходит динамическое развитие текста [Юзмухаметова, 2017: 55].

Рассматривая социально-обусловленную специфику жанра, отечественные ученые приходят к выводу, что, если в нашей стране жанру эссе долгое время «приходилось» нелегко в связи с преобладанием коллективных установок над личным мнением автора, то в западном обществе, напротив, эссеистика в XX веке переживала бурный рост. Так, Р.Г Низамова и Т.А. Кильмухаметова усматривают социальные истоки жанра в буржуазном обществе и связывают его генезис с формированием «среднего класса» и пробуждением интереса к частной жизни [Низамова, Кильмухаметова, 2018: 866].

Многоликость жанра эссе приводит к постоянному появлению его новых форм, инициированных изменяющимися социокультурными и психологическими факторами. Появление англоязычного мотивационного эссе как одной из форм мотивационного дискурса можно отнести к периоду постмодернизма, общее дискурсивное пространство которого отмечено особым стремлением автора любого сообщения воздействовать на получателя информации. Такой подход вытекает из трактовки самого понятия мотивации, который сложился в западной психологии (К. Халл, Э. Толмен, Б. Скиннер и др.) и согласно которому мотивация означает процесс, стимулирующий и поддерживающий поведенческую активность человека на определенном уровне.

Синтезирование мотивационной дискурсивнопрагматической направленности текста с жанром эссе, предполагающем опору на личностную трактовку исследуемой проблемы, позволяет эффективно переводить, как отмечает Ю.В. Гилясев, модальность речи «из поля субъективных восприятий в поле объективного знания», выделяя в тексте эссе одни факты и подавляя другие с целью убеждающего подтверждения авторских взглядов [Гилясев, 2018: 1098]. Автор мотивационного эссе, опираясь на мифологическое представление о мире, которое характерно для современной культуры и языка, представляет свое прочтение реальности, основанное на эмоциональном восприятии мира. Доверие к изложенной в таком произведении информации обусловлено природой мифа, поскольку миф - это предмет веры и доверия к авторитету и на него ограничено действуют законы формальной логики [Ильинова, 2012: 184-185].
Отсюда мотивационное эссе - это малая жанровая форма, посвященная актуальной теме и нацеленная на убеждение реципиента текста в принятии выражаемых автором идей, объективность и верификация которых создается не путем рационального анализа, а за счет использования широкого арсенала риторических средств языка.

Так, в своем мотивационном эссе «Как эго может стать нашим врагом» Райан Холидей, постулируя, что именно в человеческом эго заложено основное зло, препятствующее успешному развитию и самосовершенствованию личности, предлагает в ходе повествования основные рецепты освобождения от этого зла. С помощью каких языковых средств американский эссеист реализует ведущую функцию персуазивности в своем мотивационном произведении?

Анализируя стиль данного эссе, мы отмечаем, прежде всего, его значительную информационную насыщенность, участвующую в формировании «доказательной базы». Для него характерно широкое использование имен людей, организаций, географических названий, дат, чисел, сокращений, интернационализмов, неологизмов и т.п. Например, в тексте Райана Холидея содержатся многочисленные данные об известных личностях разных исторических эпох (Isocrates, Adam Smith, William Tecumseh Sherman, Abraham Lincoln, Steven Pressfield, Sun Tzu, von Clausewitz и др.); цитаты из их речей и трудов (Facts are better than dreams, as Churchill put it; Those who know do not speak. Those who speak do not know (Lao Tzu)); важнейшие в американской и международной истории события и места (Civil War (1861-1865), the Battle of Bull Run, Pickett's cavalry charge, Operation Desert Shield и др.); многочисленны и примеры неологизмов: startup, Facebook, Twitter, tweet, iPhones, blogger, reblogging.

Как мы видим из примеров, Райан Холидей широко использует прием интертекстуальности, который, как известно, является важнейшей характеристикой постмодернистской организации материала в работах различной жанровой направленности. Цель такого подхода объясняется стремлением автора придать объективности своим идеям, продвинуть собственную концепцию в обрамлении вызывающих доверие прецедентных текстов.

Среди стилистических особенностей произведения Райана Холидея обилие общественно-политической лексики, клишированных выражений, журналистских штампов, стандартных терминов и названий, что позволяет отнести произведение к публицистическому эссе, например: authority, US President, protégé, guru, grandiose, to corrupt values, politics, image, success, real accomplishment, the access to the CEO, military bases, 
Pentagon. Вместе с тем, поскольку автор эссе «Как эго может стать нашим врагом» не только выражает собственные мысли по актуальному вопросу в публицистическом стиле, но и художественно их оформляет, можно определить стиль произведения как художественно-публицистический.

Анализ мотивационного эссе Райана Холидея позволяет выявить немало примеров словотворчества, использования изобразительно-выразительных средств языка, вносящих в текст экспрессивность и отражающих индивидуальный стиль автора. Например:

- рифма, аллитерация: The book was a best seller, the campaign a failure. It is poise, not pose.

- фразеологизмы и их авторская трансформация: As it happened, Shakespeare's words also made their way to a young United States military officer. Like Demonicus, he was taken under the wing of a wise, older man. Известное выражение из трагедии «Гамлет»: "To be or not to be" трансформировано в "To be or to do";

- метафоры: It's why you've landed in the prestigious university. He had no taste for politics. He broke form. Where they are both divorced from reality. To pull off the mysterious veil of self-delusion;

- антитеза: Where Sherman had once been cautious, he was now confident. The greatest thing in the smallest compass. Be slow in deliberation, but be prompt to carry out your resolves;

- эпитеты: the life-altering success, a haunting sense of doubt, his connected father;

- сравнения: Be natural and yourself and this glittering flattery will be as the passing breeze of the sea on a warm summer day;

- повторы: Sitting there staring, mad at yourself, mad at the material because it doesn't seem good enough and you don't seem good enough. Talking, talking is always easy.

В стремлении воздействовать на читательскую аудиторию автор мотивационного произведения нередко предлагает игру со смыслами, воплощенную с помощью разнообразных риторических приемов, которые в большей степени характерны для художественной литературы.

Призывая читателя искать причину всех его возможных проблем внутри себя и прежде всего в своем эгоизме, препятствующем индивиду стать рациональным, объективным и здравомыслящим, Райан Холидей постоянно обращается к читателю и пытается вовлечь его в диалог, прибегая к разговорному стилю коммуникации:

- Imagine that - an ambitious person turning down a chance to advance in responsibilities. Is that really so crazy?

- The speech, if you happen to have heard it, wraps up with this little verse.
Отметим, что приемы мотивации читателя осуществляются различными способами - в виде советов, команд, наставлений и часто реализуются с помощью повелительного наклонения, модальных глаголов, мотивационных вопросов, например:

- Plug that hole - that one, right in the middle of your face. You must practice seeing yourself with a little distance.

- Doing great work is a struggle. Talk depletes us.

- Will you be able to make the most of it? Or will you be your own worst enemy? So which type of person will you be?

Часто авторские идеи, четкие и лаконичные, напоминают установки, используемые в нейролингвистическом программировании и направленные на достижение индивидом превосходства во всем, развитие его умения опережать соперников и достигать совершенства, например: "Greatness comes from humble beginnings; it comes from grunt work. It means you're the least important person in the room-until you change that with results."

Поскольку к характерным особенностям эссе относят отсутствие классического сюжета, акцент на выражении собственного мнения по поводу актуальной проблемы, имитацию живого разговора, эмоциональность и образность языка, то произведение Райана Холидея можно с уверенностью отнести к жанру научно-популярной эссеистики. На основании представленных примеров мы приходим к выводу о приоритетной эмоционально-чувственной интерпретации фактов и сведений, которые использует автор произведения мотивационного жанра.

Указанные особенности англоязычного мотивационного эссе, рассмотренные на примере жанра публицистического эссе, необходимо учитывать в процессе перевода на русский язык. По нашему мнению, переводчику в процессе работы над подобными текстами необходимо обратить внимание на ряд факторов, а именно:

- автор мотивационного эссе использует известные слова и словосочетания в несвойственном им значении, что вызвано его стремлением образнее и ярче представить свою систему взглядов;

- трудности при переводе могут быть вызваны стилистической сложностью произведения, включающей различные стили речевой коммуникации;

- в связи с частотным употреблением слов широкой тематики у переводчика может возникнуть сложность в выявлении единственно правильного значения, формируемого личностным представлением автора о мире;

- переводчику необходимо учитывать преобладание эмоционально-оценочных коннотаций над денотативным компонентом в значении слов;

- при переводе фразеологизмов важно обратить 
внимание на их творческое преобразование, что позволяет автору вводить в эссе дополнительные смыслы в высказывания;

- широкое использование автором мотивационного эссе разнообразных реалий, например, имен известных исторических и современных личностей, географических названий, названий битв, военной техники, организаций, смартфонов, интернет-таблоидов и т.п., требует от переводчика высокого уровня общекультурной подготовки и знания трансформаций, применяемых при переводе реалий;

- перевод мотивационной литературы требует от переводчика применения приема целостного преобразования в связи с общей направленностью текста в сторону убеждения читателя, изменения его ценностных установок под влиянием авторской концепции.

\section{ЛИТЕРАТУРА}

1. Гилясев Ю.В. Англоязычная мотивационная литература в контексте постмодернистской традиции // Ученые записки Казанского университета. Серия: Гуманитарные науки, 2018. - Т. 160. - Кн. 5. - С. 1097-1108

2. Добрянская А. Пять эссе для переосмысления действительности: Бродский о скуке, Уэллс об умничанье и Эмерсон о доверии к себе // Онлайн-портал «Теории и практики». - Режим доступа: https://theoryandpractice.ru/posts/7434-5-esse (дата обращения: 15.05.2021)

3. Ильинова Е.Ю. Мифологема как эвристический прием интерпретации когнитивной картины мира // Studia Linguistica: Сб. науч. тр. - СПб.: Политехникасервис, 2012. - Вып. XXI: Антропоцентрическая лингвистика: проблемы и решения. - С. 184-194

4. Каримова Р.А. Специфика дискурса в жанре эссе // Вестник Башкирского университета, 2019. - Т. 24. - № 4. - С. 872-876

5. Низамова Р.Г., Кильмухаметова Т.А. Эссе - востребованный жанр // Вестник Башкирского университета, 2018. - Т. 23. - № 3. - С. 865 -869

6. Тихонова Ю.В. Жанр эссе в современном преломлении // Вестник Московского государственного лингвистического университета, 2016. Вып. 19 (758). - С. 69-79

7. Юзмухаметова Л.С. Жанр эссе в творчестве М. Галиева // Филологические науки. Вопросы теории и практики. Тамбов. Грамота, 2017. - №73. - С. 54-57

8. Merriam-Webster. - Режим доступа: https://www.merriam-webster.com/dictionary/essay (дата обращения: 14.05.2021)

(c) Покровская Наталья Владимировна (nataliavladimirovnapokrovskaia@gmail.com).

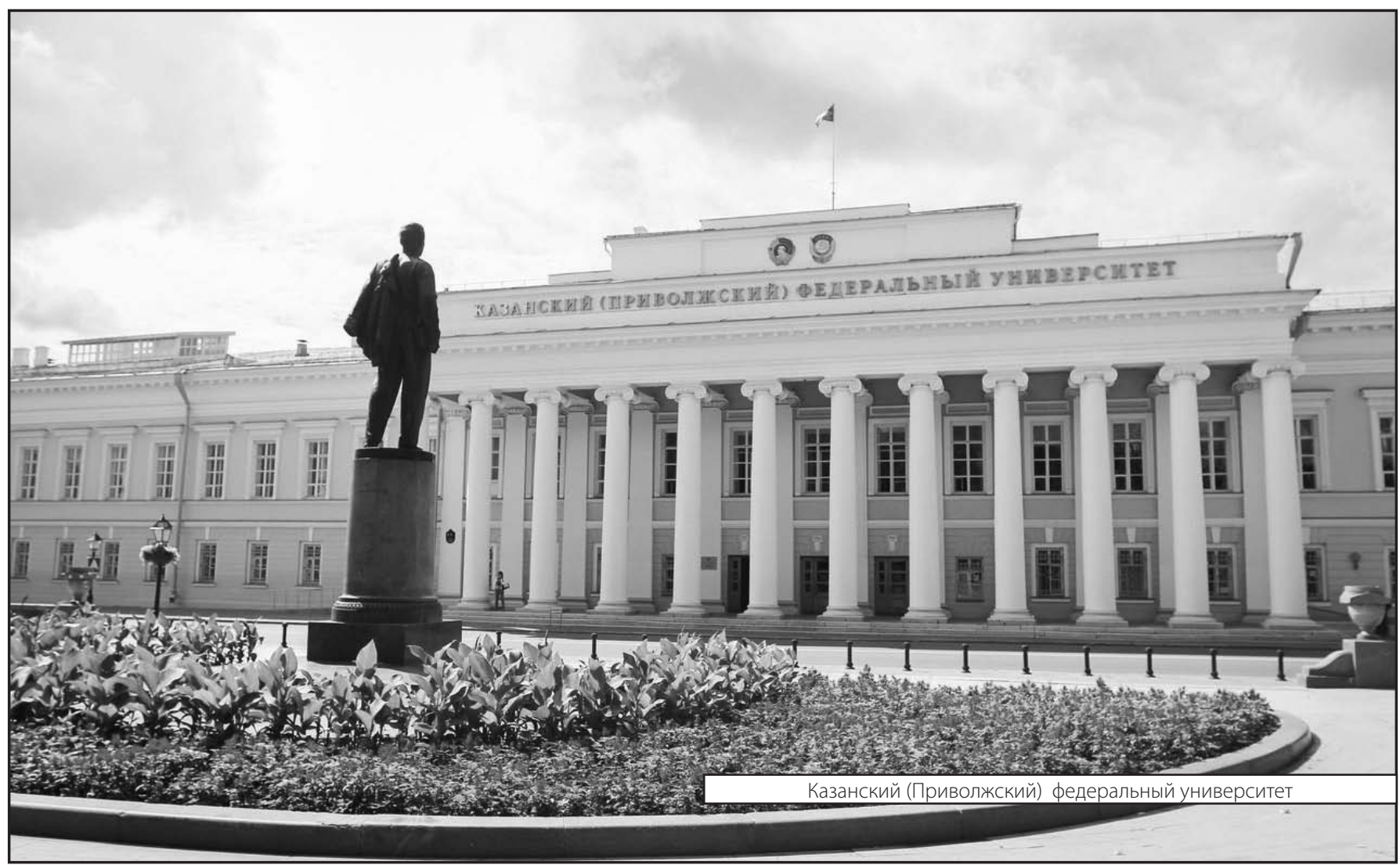

